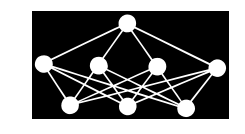

\title{
ESTIMATION OF ABLATION DEPTH IN CONCRETE SLAB UNDER REACTOR DURING NUCLEAR ACCIDENT
}

\author{
M. Vaitová, P. Štemberk
}

\begin{abstract}
The molten reactor core-concrete interaction, which describes the effect of molten reactor spread on the concrete floor of the reactor cavity, is a very complex process to simulate and predict, but the knowledge of this process is of major importance for planning the emergency counteractions for severe accidents with respect to the Stress Tests requirements after the Fukushima-Daiichi accident. The key issue is to predict the rate and most probable focusation of the melt-through process which is affected by the concrete composition, especially by the aggregate type. A limited number of small-scale experiments have been conducted over the past years along with accompanying numerical models which focused mainly on the siliceous type of aggregate. It is common for the concrete structures that the limestone type or the mixture of these two types of aggregate are used as well. Then, the objective of this paper is to extend the knowledge gained from the experiments with the siliceous aggregate to the concrete structures which are made of limestone aggregate or their combination, such as limestone sand and siliceous gravel. The proposed one-dimensional model of the melt-through process is based on the fuzzylogic interpretation of the thermodynamic trends which reflect the aggregate type. This approach allows estimating the asymptotic cases in terms of the melt-through depth in the concrete floor over time with respect to the aggregate type, which may help to decide the rather expensive further experimental efforts.
\end{abstract}

Key words: ablation depth, concrete, corium, floor slab, fuzzy logic, interaction, nuclear accident, staggered algorithm, thermal analysis

Received: January 30, 2015

DOI: $10.14311 /$ NNW.2015.25.018

Revised and accepted: July 27, 2015

\section{Introduction}

The Three Mile Island, Chernobyl and Fukushima disasters occurred with about ten years interval and showed that the most severe nuclear accidents are possible although each of these cases happened under different conditions. Since such disasters affect vast areas and have a substantial impact on environment, local

Michaela Vaitová, Petr Štemberk - Corresponding author, Faculty of Civil Engineering, Czech Technical University in Prague, Thákurova 7, 16629 Praha 6, Czech Republic, E-mail: michaela.vaitova@fsv.cvut.cz, stemberk@fsv.cvut.cz 
community as well as overall economy, the proper actions of effective countermeasures are absolutely needed and are essential. To do so, a realistic scenario and the corresponding timeline of the events during the most severe accident, which is the sudden loss of coolant, needs to be understood through a detailed analysis.

During the most severe accidents, the uranium fuel rods, the controlling mechanisms inside the reactor pressure vessel and its internals become overheated and melt into the so-called corium pool. The corium pool accumulates in the lower head of the reactor pressure vessel and can further melt through the vessel wall and spill on the concrete slab underneath in the reactor cavity, as schematically depicted in Fig. 1. The knowledge of this process is very important for civil engineers in order to be able to design efficient and consensual structures in the nuclear power plants, or estimate the times when the corium pool will melt through the base slab and leak out of the reactor cavity. In case of this accident, in order to prevent the leakage of the fission products to the environment, three scenarios are possible. The first scenario is to possess an efficient and reliable cooling system to keep the corium pool inside the reactor pressure vessel. The second scenario is to design the concrete base slab thick enough and possibly improved with special sacrificial material to contain the corium during the melting through the slab inside the containment hermetic zone. The third option is the corium catcher filled with sacrificial materials which react with corium and prevent the leakage through the containment to the outside, however, this facility is still under development and the cost of containment building rises several times.

There have been numerous simulation efforts around the world, both experimental and numerical, to simulate the melt-through of the corium pool through the concrete base slab, which are well documented in the reactor benchmarks in [1] and are discussed later. However, the results differ significantly even for similar concrete mix compositions, that means generally for the concrete with primarily siliceous or limestone aggregate. The results of these specialized algorithms indicate melt-through, or ablation, depths which differ by $100 \%$ at given decision times, or indicate differences in days when a critical ablation depth is reached, which is difficult to accept for civil engineers responsible for providing a resistant concrete structure.
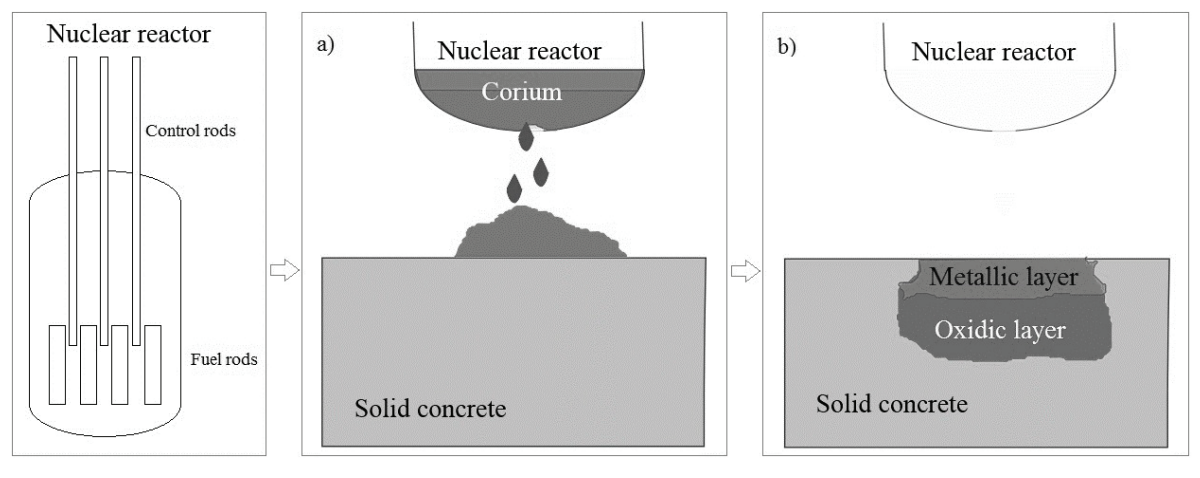

Fig. 1 Corium spill on concrete base slab. 
The civil engineer's approach to this topic is then to develop a simple and efficient method, which is based on the available information, for estimation of the ablation depth during the corium-concrete interaction which happens at elevated temperatures. Then, based on this estimation, the design of the thickness of the concrete slab under the reactor is performed or the thickness of an existing concrete slab is assessed safe or not safe.

Therefore, in this paper, a simple and efficient method for modeling the coriumconcrete interaction, when the pressure vessel ruptures and corium pool spills on the concrete base slab, is proposed. The corium-concrete interaction is covered by the coupled model of the heat transfer and the mixing of molten materials. Like this, the method offers a relatively simple tool for determination of the ablation rate of the concrete slab and whether and when corium melts through the containment floor. The heat transfer analysis is based on the finite element method while the fuzzy modeling is employed for description of material properties.

\section{Problem description}

In this section, the basic information is given which is necessary for general comprehension of the problem and derivation of the fuzzy logic model.

When the fuel rods get overheated, the corium pool forms in the lower head of the reactor pressure vessel, as depicted in Fig. 1. The corium pool stratifies into two layers, oxidic and metallic. The oxidic part of the corium pool, which contains the uranium dioxide and the zirconium dioxide, has a higher density and consequently is formed in the lower part of the corium pool. Also, the heat which is generated due to the decay of the fission products develops in the oxidic part of the corium pool. The metallic layer transfers the heat much more easily because of its high thermal conductivity so the heat generated in the oxidic part is transferred through the metallic layer to the wall of the reactor pressure vessel. This wall heating process is called the focusing effect. Then, the reactor pressure vessel wall is heated up and therefore the reactor pressure vessel may rupture under the heat and weight of the corium pool. The worst case of rupture is the failure of the entire lower head which impacts the base floor slab of the reactor cavity. This impact crushes the upper layer of the concrete slab because the lower head filled with corium pool weights tens of tons, specifically about 80 tons in case of partial meltdown, with all reactor internals the weight exceeds 188 tons. The corium pool which is formed on the top of the slab sinks as the generated heat melts concrete underneath and the corium mixes with concrete. Other types of the corium pool stratification are known, however, the stratification described above is mostly considered in current studies.

Few experiments and calculations of the corium-concrete interaction have been performed which provide limited, and also diverse, information about the coriumconcrete interaction processes. A fine example of such a summary can be found in [3] where the presented data indicate that it is far from realistic to make decision about reactor safety based on the temperature distribution and thus ablation rate which was obtained from experiments performed with analogous materials, which may be due to the very uncertain transition of the concrete-corium mixture from the solid to liquid state and the gases released from the molten concrete, which are 
then discussed in [14]. A review of such experiments, which are always downscaled from the real reactor size, can be found in $[6,15]$. Cranga in his paper [1] discusses results of these experiments and calculations with few types of the corium-concrete pools where he distinguishes the homogenized and the stratified pool with the limestone or the siliceous concrete. The additional phenomenon of oxidation of metals in the metallic layer is also discussed in [1], which is responsible for the gas release during the melting of the corium pool through the base slab. The calculation of the stratified pool in [1] also shows a faster ablation rate in both cases for the siliceous and the limestone concrete. The main cause of the faster ablation is the focusing effect, which was mentioned above, which occurs due to presence of the metals. A very important observation for the proposed modeling is that in the case of limestone concrete, the corium pool is stratified for approximately one and half days of the interaction and then most of the metals are oxidized and the corium pool becomes homogenized, and in the case of siliceous concrete, the corium pool remains stratified. Nevertheless, despite the relevant information and explanation of the melting processes, the calculations performed in [1] show different results for the same input data.

The principal differences between the silica-rich concrete and the limestone-rich concrete are well described in [6] where it is stated that the limestone-rich concrete contains the calcium carbonate $\left(\mathrm{CaCO}_{3}\right)$ which is decomposed while heated and therefore this type of concrete generates more gas than the silica-rich concrete. This phenomenon supports the idea of homogenization of the corium-concrete pool in the case of concrete with mainly limestone aggregate. Also, the liquidus, i.e. corium in the liquid state, temperature for each type of concrete is different, when for the siliceous concrete the liquidus temperature is about $1700^{\circ} \mathrm{C}$ for the limestone concrete it is about $2000^{\circ} \mathrm{C}$.

The gas flow in the molten corium-concrete pool influences the duration of the ablation. This effect was studied in [4] by a Bulgarian team. Specifically, the content of $\mathrm{H}_{2} \mathrm{O}$ and $\mathrm{CO}_{2}$ in concrete and their effect on mixing the molten pool was studied. The effect of both the components affects the duration of the axial ablation with the following tendency: the higher the content of the gas, the longer the duration of the ablation. The gas release influences the configuration of molten corium-concrete pool irrespective to whether it is stirred and thus homogenized or stratified. Also, it is pointed out in [4] that the oxidation of metals, which is caused by the gas flow, does not allow the stratification anymore. The paper [4] also presents yet another model which takes into account the important parameters of the corium-concrete interaction and utilizes the assumptions for the worst scenario when the ablation is the fastest, which fits best the civil engineer's needs for the safe design.

\section{Method of solution}

It should be stated at the beginning that the proposed numerical algorithm is designed for simulation of the meltdown of a VVER-1000-type pressurized water nuclear reactor, such as in Temelín nuclear power plant in the Czech Republic, Fig. 2. The concrete base slab at the bottom of the VVER-1000 reactor cavity is of circular shape with the diameter of about 5.5 meters. The simulation is conceived 


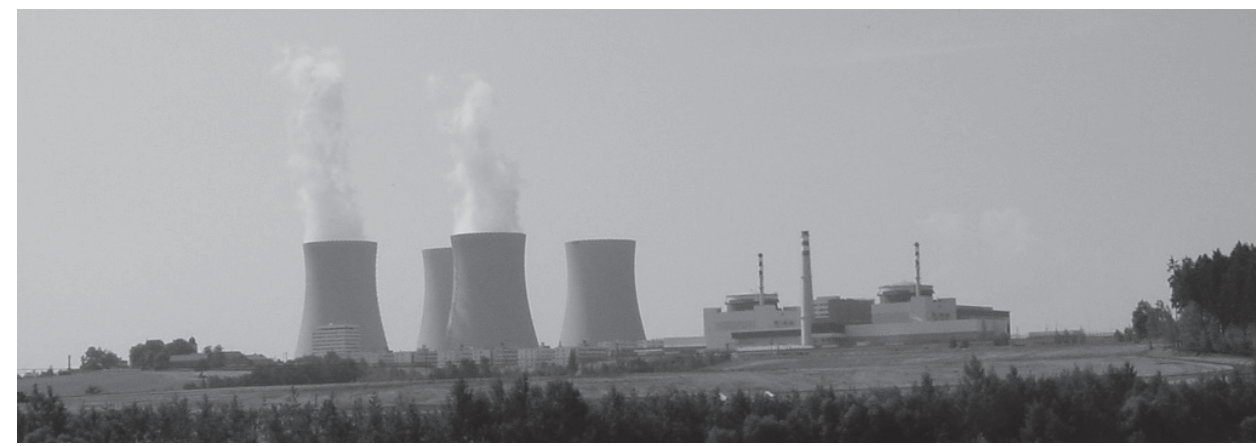

Fig. 2 Temelín nuclear power plant.

as a one-dimensional problem with the axis identical to the axis of the reactor and the axis of the slab, as can be seen in Fig. 3. There are two reasons for this decision. Firstly, the melt-through, or ablation, rate of the concrete base slab is of interest and it occurs in the vertical direction. And secondly, the reviewed results of the currently available specialized numerical simulations do not offer a clear idea about the horizontal effect of the spilled corium pool, [1]. Therefore, due to the excessive scatter of the results on the horizontal ablation and its varying shape, it was decided not to investigate the horizontal direction in detail and rather express the effect of the horizontal ablation by reduction of the decay heat available for the vertical ablation according to the ratio of the vertically ablated volume to the total ablated volume, which is estimated from the results in [1]. It should be also noted that the two-dimensional problem is more related to the structural collapse of the base slab, rather than to its penetration by the overheated corium pool. Therefore, the spread of the corium pool on the base slab is take as uniform

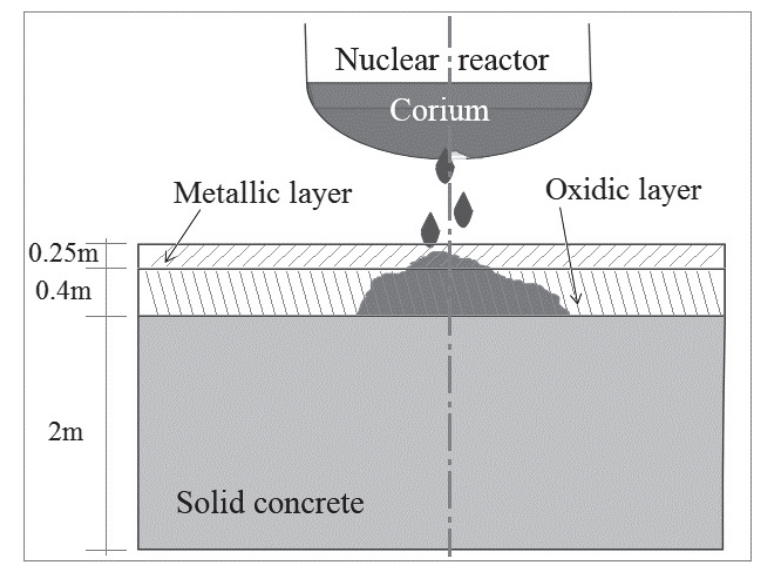

Fig. 3 Geometry of problem. 
with the corresponding heights of the metallic and oxidic (mainly uranium dioxide) layers as shown in Fig. 3.

The review of the available information on the corium-concrete interaction shows that the problem is still being solved mostly theoretically and experimentally only on small-scale tests, either of which does not provide any definite information necessary for reliable safety assessment. The description of this information as incomplete, vague, and scarce seems the exact definition of data which are best fit for processing with the fuzzy logic. Then, in accordance with the objective of this paper, it is shown that the proposed method, which makes use of the fuzzy logic, can extend the up-to-date published experimental and numerical results so that an estimate on the ablation depth and the ablation rate, which are necessary for the safety assessment, can be obtained even for the existing types of concrete which are used at the operating nuclear power plants.

The fuzzy logic, beside the other artificial intelligence techniques, such as the artificial neural network [18], has already proved itself as a very effective tool for solution of various civil engineering problems when there were no exact experimental data, the data were limited, or the historical data were extended to the current situation. Examples of these applications can be found in [7] where the risk of liquefaction of sandy soils due to earthquake was assessed, in [2] where the poorest link in the ready-mixed concrete distribution was identified, in [11] where the potential excessive deformation of a diaphragm wall was evaluated based on the past experience, in [17] where the hydration of concrete and the subsequent risk of cracking was modeled, or in $[10,16]$ where the effect of winter road maintenance and cyclic loading on stiffness of concrete in compression was modeled, to name just few examples. Therefore, the trends identified in the graphs, equations and in the discussions in $[1,3-6,8,9,12-15]$ were expressed using the fuzzy logic. In order to maintain the modeling simple, the number of the fuzzy sets was kept low and only the triangular membership functions were used. The Mamdani inference is employed and the deffuzification is done with help of the center of gravity method in all cases.

\subsection{General description of algorithm}

The ablation of the concrete base slab is computed as a coupled problem of the one-dimensional heat transfer and the mixing of materials in the melt pool. The problem is discretized into layers along the main axis as shown in Fig. 4. Each layer consists of three principal materials, which govern the melt-through process, namely, these are the metals, oxides and concrete. The amount of each of the material within the layer is expressed as its volumetric percentage in that layer, as shown in Fig. 4. The densities of each of the materials within the layer are different but their effect on the vertical position of each of the materials within the layer is not considered as the layers are defined thin enough to hold this assumption.

For the heat transfer analysis, each layer is then considered as a one-dimensional isoparametric finite element and the heat transfer analysis is governed by the thermal conductivity equation

$$
k \frac{\mathrm{d} T}{\mathrm{~d} x}+\dot{H}(t)=\varrho c \frac{\mathrm{d} T}{\mathrm{~d} t},
$$




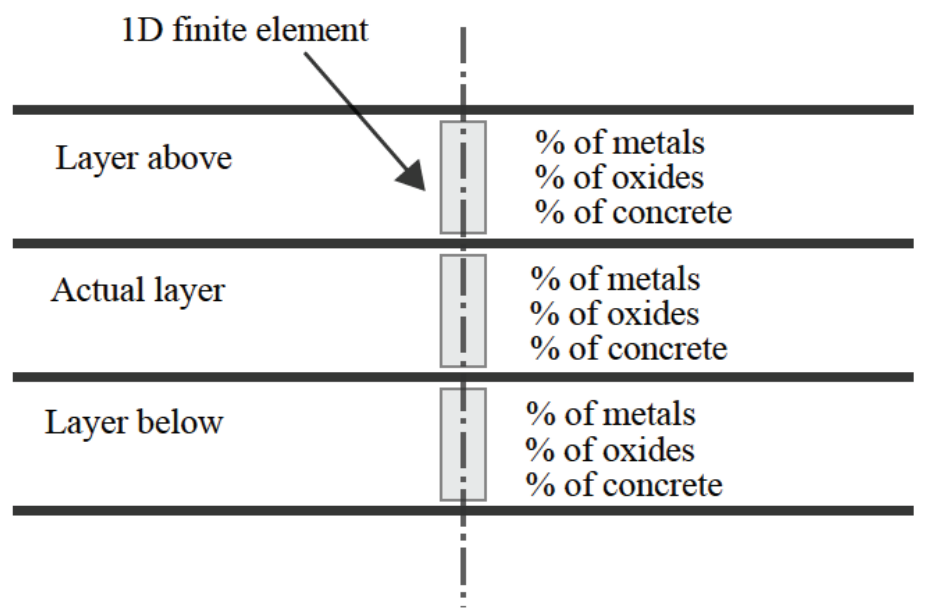

Fig. 4 Arrangement of layers and corresponding finite elements.

where $k$ is the thermal conductivity, $\rho$ is density, $c$ is the specific heat capacity, $T$ is temperature, $H$ is the fission decay heat, $t$ denotes time and $x$ is the depth. The thermal parameters, including the density and the decay heat, which are used in the heat transfer analysis, are averaged with respect to the proportional representation of each of the three materials in a finite element.

The coupled problem is solved using the so-called staggered algorithm where the heat transfer analysis is solved first and is followed by calculation of the mixing of the materials. The flow of the staggered algorithm is described in Fig. 5. The mixing is performed at each time step and it is expressed by mutual exchange of the volumetric proportions of the three materials between the actual layer and the layer above (see Fig. 4), which runs as a loop from the lowermost layer up to the upper surface. Then, the material parameters used in the heat transfer analysis are reevaluated and used for the heat transfer analysis in the next time step. Therefore, the length of the time step with respect to the thickness of the layer needs to be carefully selected with respect to convergence of the algorithm. Based on the numerical testing of the algorithm stability, it was found that the longest possible time step is equivalent to about 10 minutes with the corresponding thickness of the layer of $5 \mathrm{~cm}$. Due to the use of fuzzy logic, it is tedious to derive an analytical convergence criterion for the developed algorithm, therefore the numerical testing of the algorithm for all possible ranges of the parameters is taken as a sufficient proof of the convergence.

\subsection{Two mechanisms of mixing}

While the heat transfer analysis is quite straightforward, the mixing of the materials in the melt pool comprises two different mixing mechanisms which are described using several parameters with highly nonlinear behavior, which are defined below. 


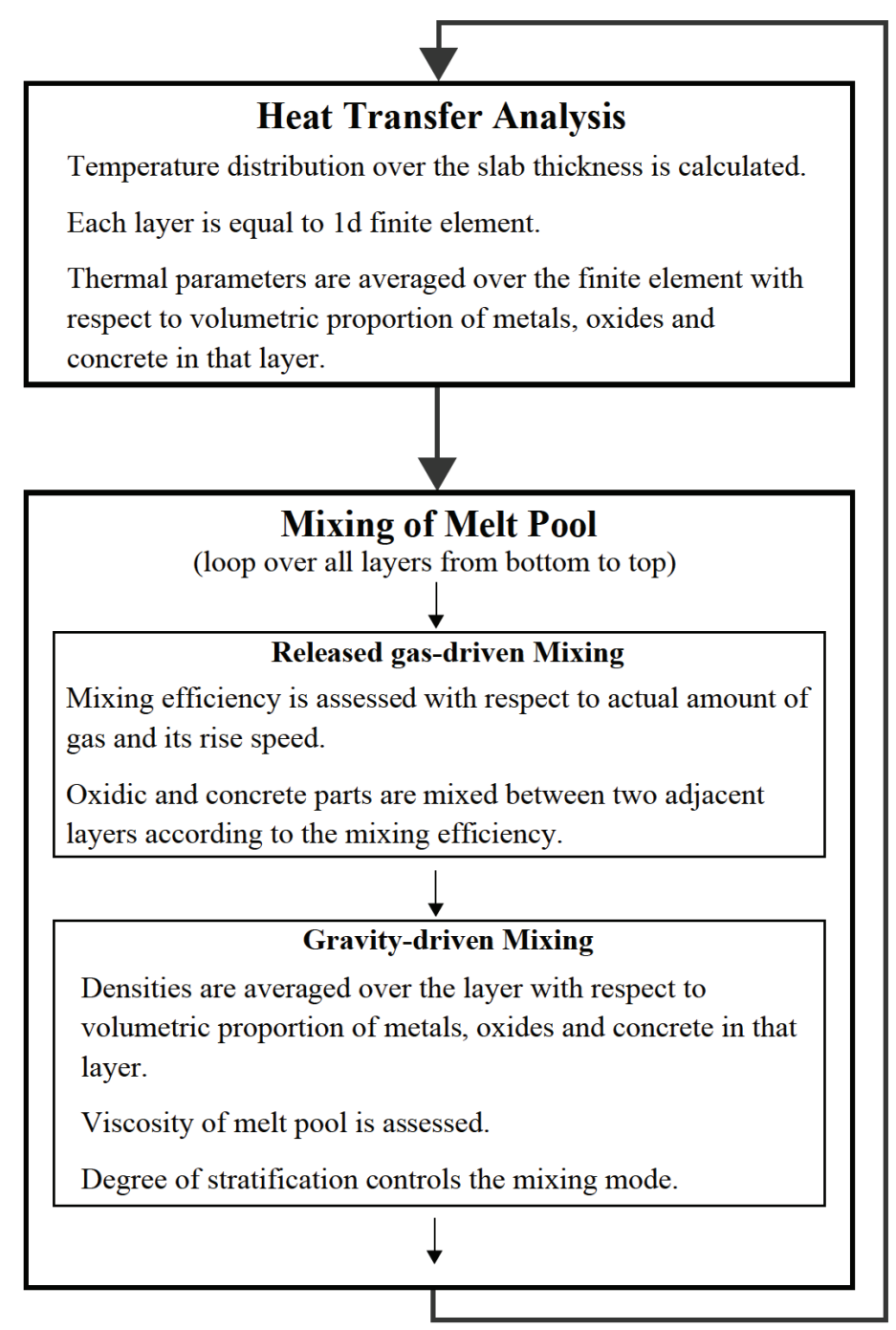

Fig. 5 Flow chart of the staggered algorithm.

The two mixing mechanisms differ in their driving forces. The first mechanism is driven by the gravity and the other by the stirring which comes with the bubbling gas released from the molten concrete. Those two mixing mechanisms define the way how the material (metals, oxides and concrete) proportions are exchange between the two adjacent layers.

The first, gravity-driven, mechanism is controlled by the densities, viscosity and the degree of stratification. The density of a layer is obtained as the weighted average of the densities according to the proportions of the three materials in the layer. The viscosity is defined by fuzzy logic as explained in the following section. 
The degree of stratification is proportional to the content of the limestone and siliceous aggregate in the used concrete when this parameter controls how much of the metallic part can mix with the other two parts (oxidic and concrete) in a layer. The extreme cases are the stratified distribution for the degree of stratification equal to 0 when only siliceous aggregate is used and homogeneous distribution for the degree of stratification equal to 1 when only limestone aggregate is used. Then, in the algorithm, the degree of stratification equal to 0 means a mere swap of the actual proportion of the metallic part between the two adjacent layers and the degree of stratification equal to 1 means full mixing of the actual proportion of the metallic part with the other two materials in the two adjacent layers. Any value of the degree of stratification between 0 and 1 defines how much of the actual proportion of the metallic part will be mixed with the other two materials.

The second, bubbling gas-driven, mechanism is controlled by the mixing efficiency of the rising gas, which is defined in the following sections. The parameter denoted as the mixing efficiency accelerates the mixing of oxides with molten concrete and in the algorithm, the mixing efficiency is defined as a multiplier which increased the mixed shares of the oxidic and the concrete parts of the two adjacent layers. As a result, the metallic layer would sink below the oxide-concrete mixture much faster, provided that the degree of stratification parameter would be close to 0 . If the degree of stratification parameter is close to 1 , the metallic part would mix much faster with the oxides and the concrete to form a homogeneous melt pool.

\subsection{Fuzzy-logic description of gravity-driven mixing}

The gravity driven mixing depends mainly on viscosity of the melt pool which consists of a mixture of molten concrete and corium pool. The volumetric proportion of molten concrete to the corium pool changes with the progressing ablation of the concrete base slab and so the viscosity changes. The viscosity also depends on temperature. The experimental data which are available in $[12,13]$ for description of the dependence of viscosity on concrete-corium ratio and temperature are shown in Figs. 6 and 7. Generally, viscosity describes the relation between the velocity of material flow and the shear stress on the interface of the material layers. The Newton's viscosity law says that the stress between the layers depends on the dynamic viscosity and the velocity gradient. The data presented in [13] describe specifically the temperature ranges when the corium-concrete mixture turns from solid to liquid state, shown in Fig. 6 where the lower curves define the solid behavior of the mixture and the upper curves specify when the mixture is totally liquid. The area enclosed between the curves defines the so-called mushy zone where the solid and also the liquid phase are present within the mixture. The experimental data by Seiler, [12], shown in Fig. 7 give a hint on the trends between the viscosity of the corium-concrete mixture and its temperature and the proportional amount of concrete in the mixture. It can be noted that the viscosity of the corium-concrete mixture is strongly dependent on the content of concrete in the mixture, when more concrete in the mixture means higher viscosity at the same temperature and, the lower the temperature, the higher the viscosity.

Based on these experimental data (Figs. 6 and 7), the fuzzy rules can be derived for providing the relation between the corium-concrete mixture configuration and 
Temperature $[\mathrm{K}]$

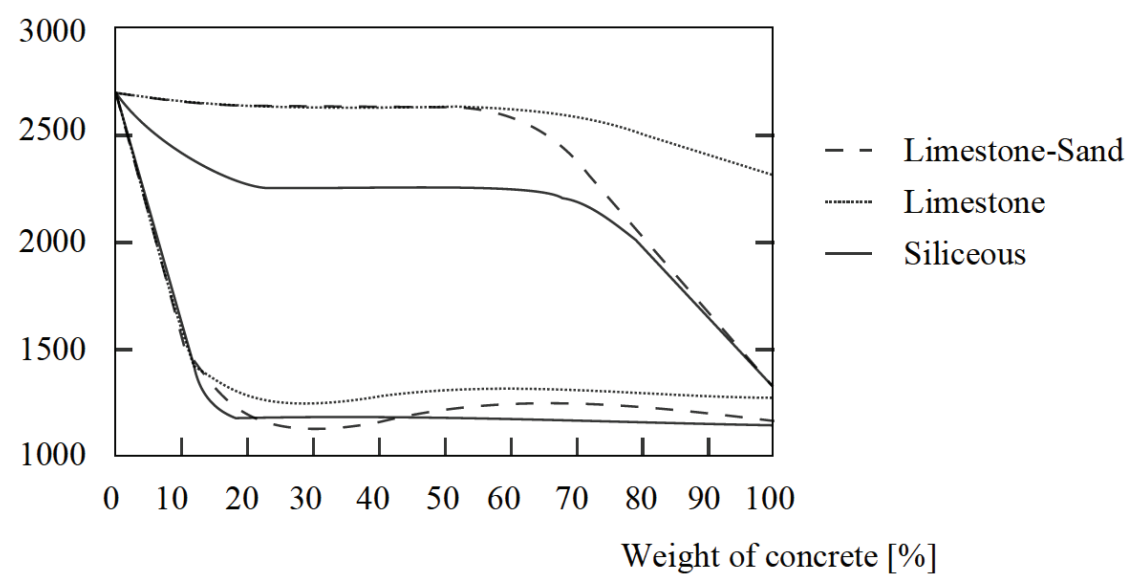

Fig. 6 Solidus and liquidus temperatures, [13].

Viscosity $[\mathrm{Pa} \cdot \mathrm{s}]$

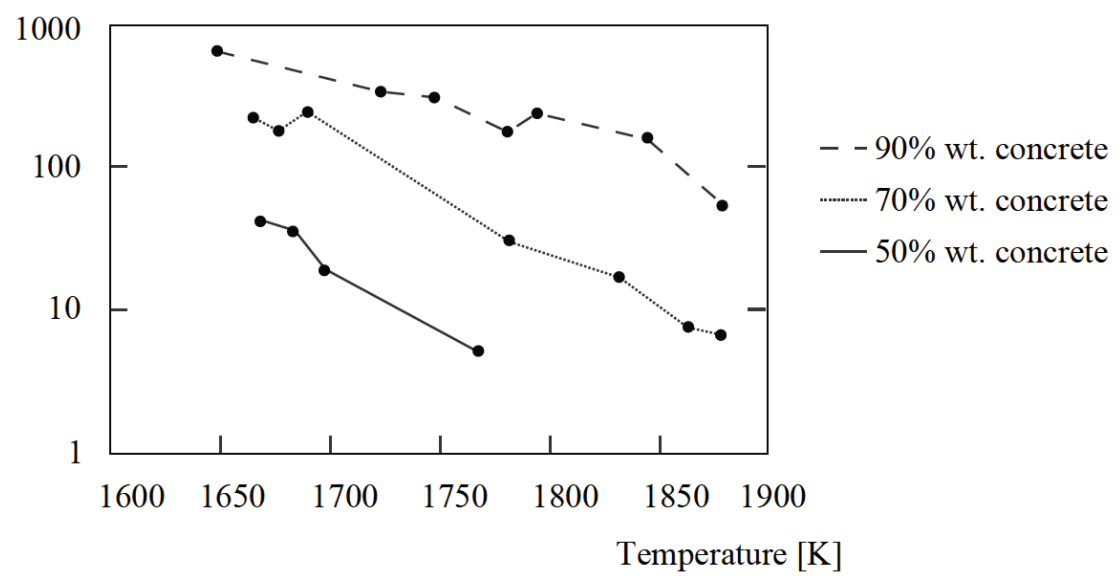

Fig. 7 Viscosity of siliceous concrete, [12].

temperature and the corresponding viscosity of the corium-concrete mixture. It should be noted that viscosity describes the ease of the mixture to be moved, which in the algorithm is described by the mutual exchange of the volumetric proportions of the two adjacent layers. The fuzzy model of viscosity, $\nu$, schematically described in Fig. 8, considers the two input quantities: temperature, $T$, and density, $\rho$, of the corium-concrete mixture at a given location. The density is proportional to the concentration of concrete which is melted in corium pool. The output quantity is 


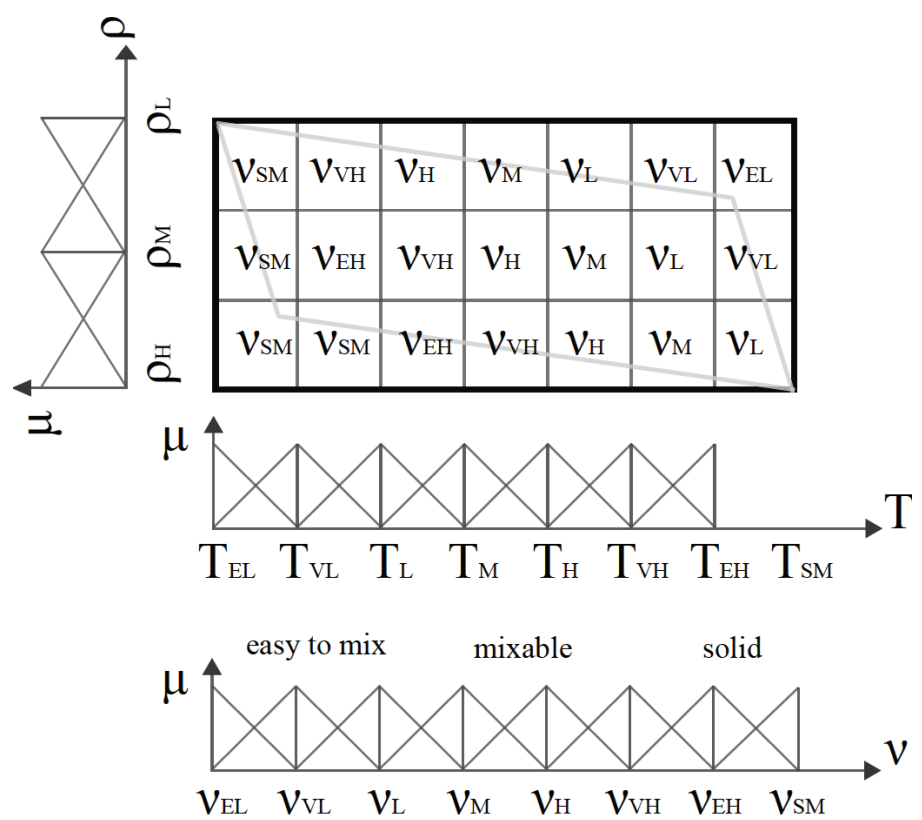

Fig. 8 Scheme of fuzzy logic model for viscosity of corium-concrete mixture.

the viscosity, $\nu$, which affects directly the rate of sinking of the corium within the pool in the numerical analysis. Since the type of aggregate, namely the siliceous and limestone types, affect the viscosity, as can be seen in Fig. 6, the decision-making table shown in Fig. 8 is defined twice for the respective type of the aggregate. If concrete consist of either of the types of the aggregate, then the respective table is used. If concrete uses both types of the aggregate, then both tables are employed and the two resulting viscosities are averaged with respect to the weights of the two types of aggregate which is used in the concrete. Tab. I shows the example of the medium values (the degree of membership, $\mu$, is equal to unity) of the fuzzy sets for concrete with the siliceous type of aggregate, shown in Fig. 8.

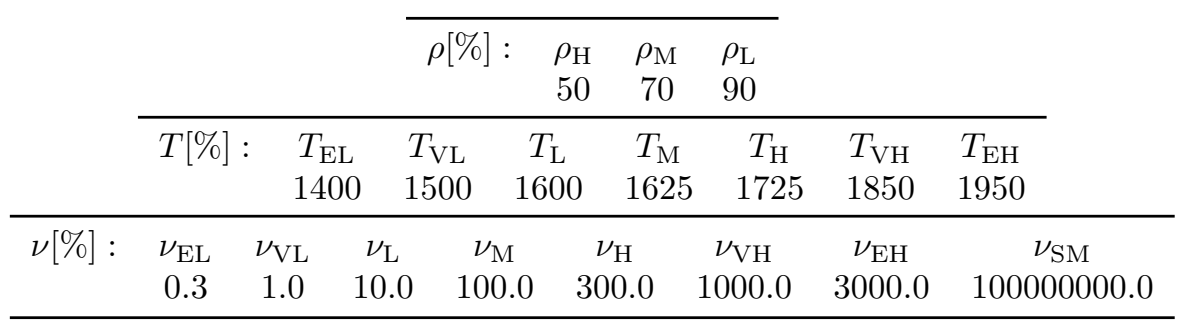

Tab. I Medium values for fuzzy sets of viscosity, temperature and density. 


\subsection{Fuzzy-logic description of released-gas-driven mixing}

The basic mixing mechanism in this case is the bubbling gas which rises through the melt pool from the ablated concrete at the bottom of the pool. There are two primary gases which need to be considered when the mixing efficiency is assessed. The first is steam which comes from both the free and chemically bound water in concrete, [9]. The amount of free water is directly related to porosity of concrete, which is usually up to $5 \%$, and the relative humidity. Then, the maximum amount of free water in one cubic meter of concrete may be about $50 \mathrm{~kg}$ when concrete is fully saturated, and $0 \mathrm{~kg}$ when concrete is dry. The amount of chemically bound water, which is a part of the C-S-H gel, is about $40 \mathrm{~kg}$. Then, there is about $90 \mathrm{~kg}$ of water which will turn into steam when heated above $100^{\circ} \mathrm{C}$ out of one cubic meter of concrete. The chemically bound water is released at the temperature ranging from 180 to $850^{\circ} \mathrm{C}$, while concrete melts at the temperature of about $1200^{\circ} \mathrm{C}$.

The other gas is $\mathrm{CO}_{2}$ (carbon dioxide), which is released from the limestone aggregate at the temperature ranging from 600 to $900^{\circ} \mathrm{C}$, and its amount in one cubic meter of concrete is about $750 \mathrm{~kg}$, [9]. In the case of siliceous aggregate, the amount of released $\mathrm{CO}_{2}$ is negligible.

The mixing efficiency of the released gas depends mainly on the speed at which the gas rises and on the amount of the released gas, [8]. The rise speed then can be defined as a function of viscosity of the corium-concrete mixture. However, the measured data on viscosity of the corium-concrete mixture is very limited, [12, 13], and so the viscosity was defined by the fuzzy logic according to the recognized trends in the experimental data introduced in the previous section, so that the range of applicability of the viscosity parameter became wider. Therefore, it is reasonable to define the rise speed also as dependent on temperature and the corium-concrete ratio, similarly to the fuzzy definition of viscosity in the previous section, as can be seen in Fig. 9.

The amount of $\mathrm{CO}_{2}$ is proportional to the amount of limestone aggregate in concrete. Since it happens that the limestone and siliceous aggregates can be both used in the same concrete mixture, such as limestone sand and siliceous gravel, the amount of $\mathrm{CO}_{2}$ depends on the weight ratio of the limestone and siliceous aggregate, and thus it ranges from $750 \mathrm{~kg}$ to $0 \mathrm{~kg}$. The thermal criterion of release of $\mathrm{CO}_{2}$ is set at $800^{\circ} \mathrm{C},[9]$.

The amount of steam, which can be then merely added to the amount of $\mathrm{CO}_{2}$, also depends mainly on temperature. However, in the case of free water, the actual amount available in the pores also depends on the moisture content. Therefore, the steam from the free water is released at the exact temperature of $100^{\circ} \mathrm{C}$ and its amount depends on the moisture content, or the relative humidity. In the case of the chemically bound water, the available amount is taken as dependent on the water-cement ratio (ratio given in $\mathrm{kg} / \mathrm{kg}$ ) which is used in concrete and it is released at the exact temperature of $400^{\circ} \mathrm{C}$, which lies within the temperature interval when most of the hydrates are dehydrated, [9]. The total amount of gas is then taken as the sum of steam and $\mathrm{CO}_{2}$ which are released at the actual temperature of concrete at a time step. The mixing efficiency, as a parameter which enters the calculation, is obtained from another fuzzy-logic description of the trends recognized in the experimental data and their discussion in $[8,14]$. The mixing efficiency is given by the fuzzy rules shown in Fig. 9 which basically express the natural upward flow of 
Vaitová M., Štemberk P.: Estimation of ablation depth in concrete slab under...

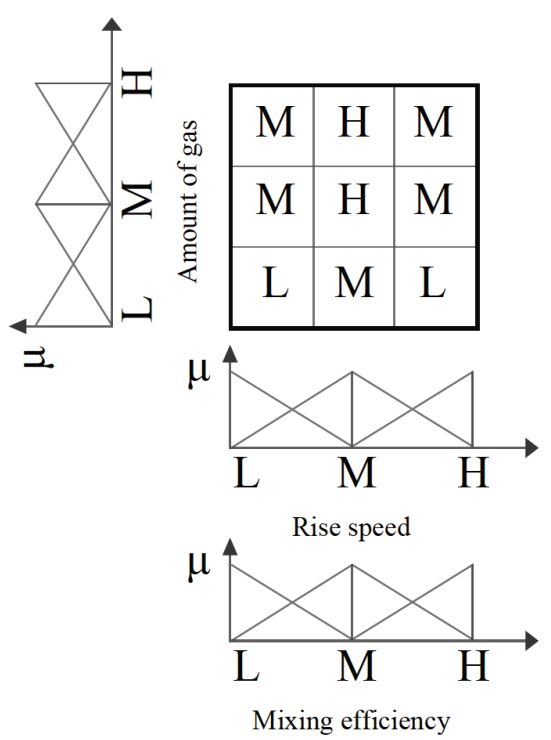

Fig. 9 Scheme of fuzzy logic model for mixing efficiency of released gases.

\begin{tabular}{lccc}
\hline & Low & Medium & High \\
\hline Amount of gas in concrete $\left[\mathrm{kg} / \mathrm{m}^{3}\right]$ & 0 & 375 & 750 \\
Rise speed [cm/s] & 1.50 & 3.15 & 4.80 \\
Mixing efficiency [-] & 1 & 2 & 3 \\
\hline
\end{tabular}

Tab. II Medium values for fuzzy sets of mixing efficiency, rise speed and amount of gas.

gas through a liquid or semi-liquid corium-concrete mixture, when moderate rise speed with a high amount of gas shows the best mixing performance. At higher rise speeds, the bubbles tend to localize in to a continuous stream of gas which rises through a single or sever channels and thus the mixing efficiency is reduced. Also, when the rise speed is low and the amount of gas is small, the mixing efficiency is low, as can be seen in Fig. 9. Tab. II gives the medium values (the degree of membership, $\mu$, is equal to unity) for the fuzzy sets defined in Fig. 9.

\section{Example of application of proposed method to VVER-1000 reactor cavity floor slab}

The applicability of the proposed simulation method is shown in an example of calculation of the melt-through of corium pool through the concrete base slab at the bottom of the reactor cavity for two limit cases which differ in the type of 
the aggregate, which develop either a homogenized or stratified melt pool. The simulations were run in Matlab.

The thickness of the concrete base slab is taken as 2 meters and the objective of the two following examples is to estimate the ablation rate of the concrete slab. While the geometry of the problem is constant, all material parameters which enter the analysis vary with temperature and the changing composition of the melt pool. For example, the density of concrete is $2500 \mathrm{~kg} / \mathrm{m}^{3}$ under normal conditions but with increasing temperature its density decreases to $2200 \mathrm{~kg} / \mathrm{m}^{3}$. The thermal conductivity of concrete varies between 2.5 and $1.1 \mathrm{~W} / \mathrm{m} / \mathrm{K}$ and also decreases with increasing temperature. The specific heat of concrete depends on the aggregate type. The limestone aggregate has a lower specific heat than the siliceous aggregate. For the limestone concrete, the specific heat varies between 800 and $600 \mathrm{~J} / \mathrm{kg} / \mathrm{K}$, when under normal conditions it is $800 \mathrm{~J} / \mathrm{kg} / \mathrm{K}$ and at elevated temperatures it decreases to $600 \mathrm{~J} / \mathrm{kg} / \mathrm{K}$. The specific heat of the siliceous concrete varies between 800 and $1300 \mathrm{~J} / \mathrm{kg} / \mathrm{K}$, when the specific heat increases with increasing temperature. The oxidic part of corium pool contains the uranium dioxide and zirconium dioxide which results in a density of about $8500 \mathrm{~kg} / \mathrm{m}^{3}$. The thermal conductivity of the oxides is about constant $10 \mathrm{~W} / \mathrm{m} / \mathrm{K}$ and the specific heat varies between 300 and $500 \mathrm{~J} / \mathrm{kg} / \mathrm{K}$, when it increases with increasing temperature. The metallic part of the corium pool is lighter than the oxidic part with its density of about $6000 \mathrm{~kg} / \mathrm{m}^{3}$. The thermal conductivity of the metallic part is much higher than that of the oxides and concrete and is considered as constant $40 \mathrm{~W} / \mathrm{m} / \mathrm{K}$. The specific heat of the metallic part is constant $900 \mathrm{~J} / \mathrm{kg} / \mathrm{K}$. All these values and their trends were taken from $[5,8,9,13]$.

In the first limit case, only the limestone aggregate is used in the concrete which results in a fully homogenized melt pool. Fig. 10 shows the development of density within the homogenized pool along the thickness of the slab over time. At the beginning, the pool is stratified into two layers when the metallic layer is above the oxidic layer. Then, the two materials start mixing gradually. Also, with the progressing ablation, the molten concrete with the lowest density is visible under the melt corium pool. Since the heat conduction is faster than the rate of mixing, it can be observed in Fig. 10 that the amount of the molten concrete increases under the corium pool. Thus the difference between the rates of the mixing efficiency and the heat conduction is evidenced. The melt pool density decreases gradually with time and so the gravity-driven mixing becomes slower. The total ablation (full penetration) of the slab occurs after 40 hours. The corresponding development of temperature over time is shown in Fig. 11 where the top layer of the pool suffers from the heat losses to the ambient air. The metallic part of the melt pool has much higher thermal conductivity than the other two materials, therefore, the heat losses are greater when the metals constitute the top layer. At about 23 hours, the metals start to mix with the rest of the melt pool, i.e. with the oxidic and concrete parts. Since the oxides and concrete have lower thermal conductivity, they serve as thermal insulation which results in a faster increase of temperature within the melt pool.

In the other limit case, only the siliceous aggregate is used in the concrete which results in a stratified melt pool. The stratification of the melt pool is shown in Fig. 12. The stratification, i.e. separation of the metal parts from the oxidic 
Vaitová M., Štemberk P.: Estimation of ablation depth in concrete slab under...

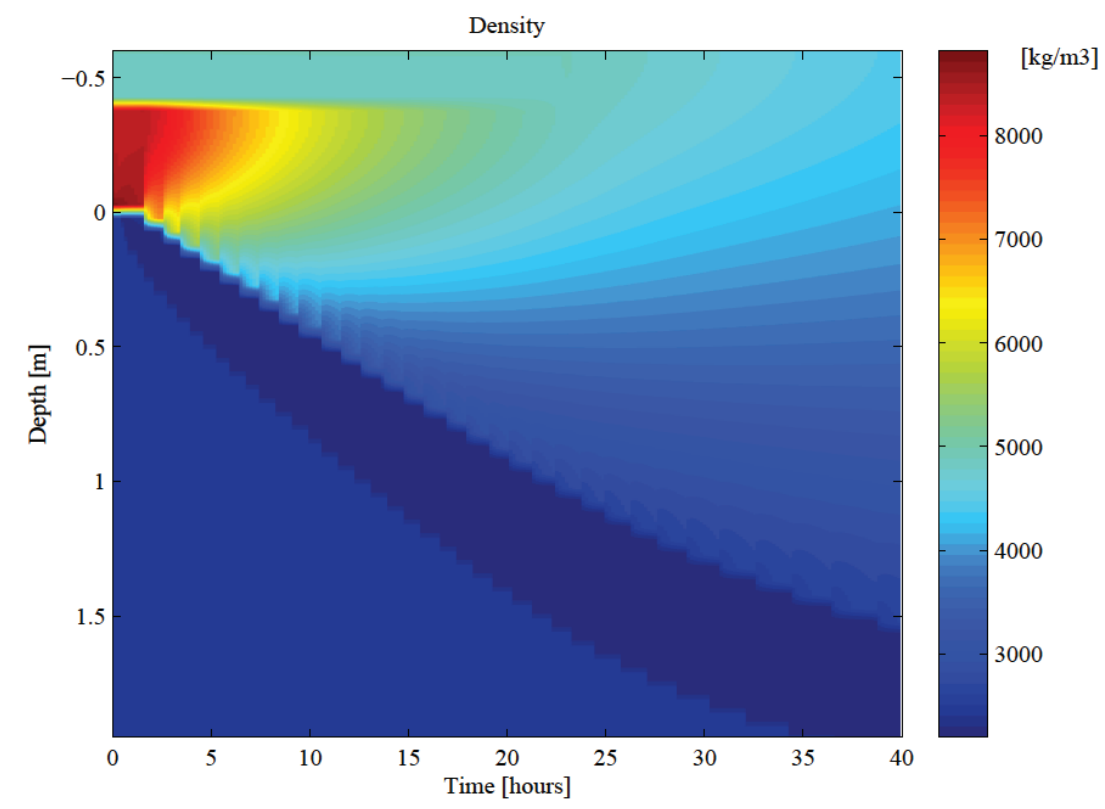

Fig. 10 Development of density for case with only limestone aggregate.

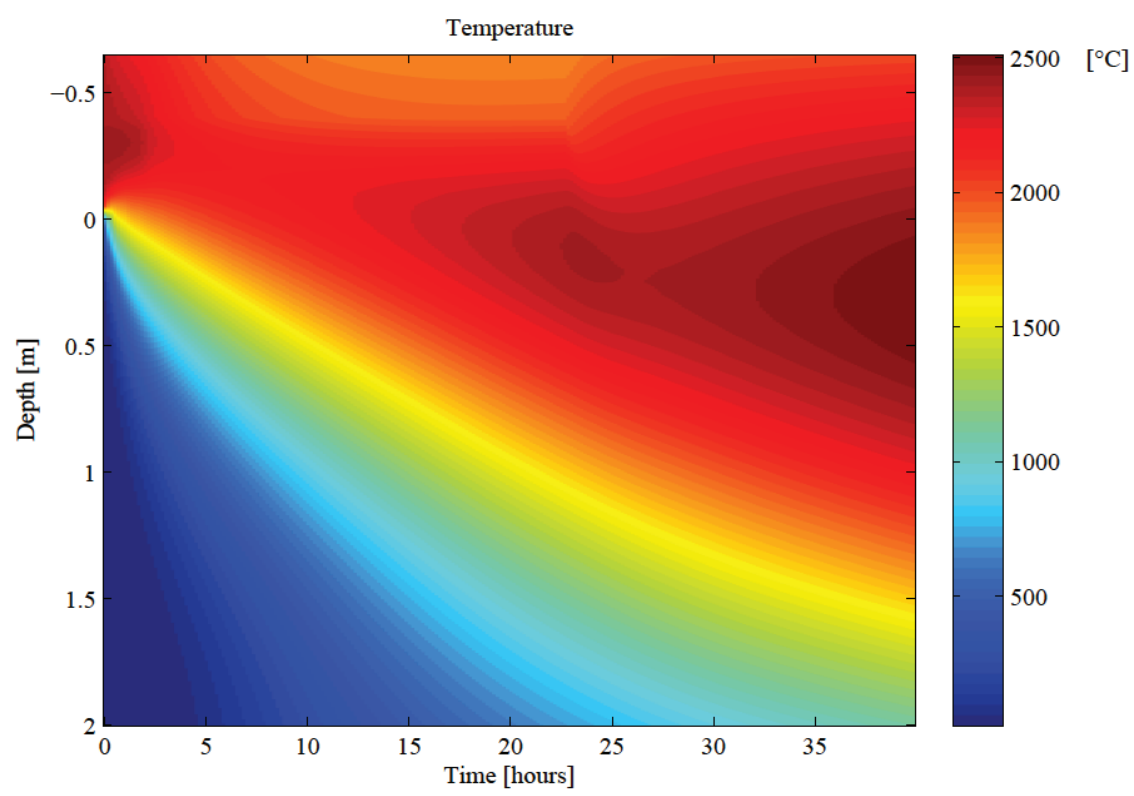

Fig. 11 Development of temperature for case with only limestone aggregate. 


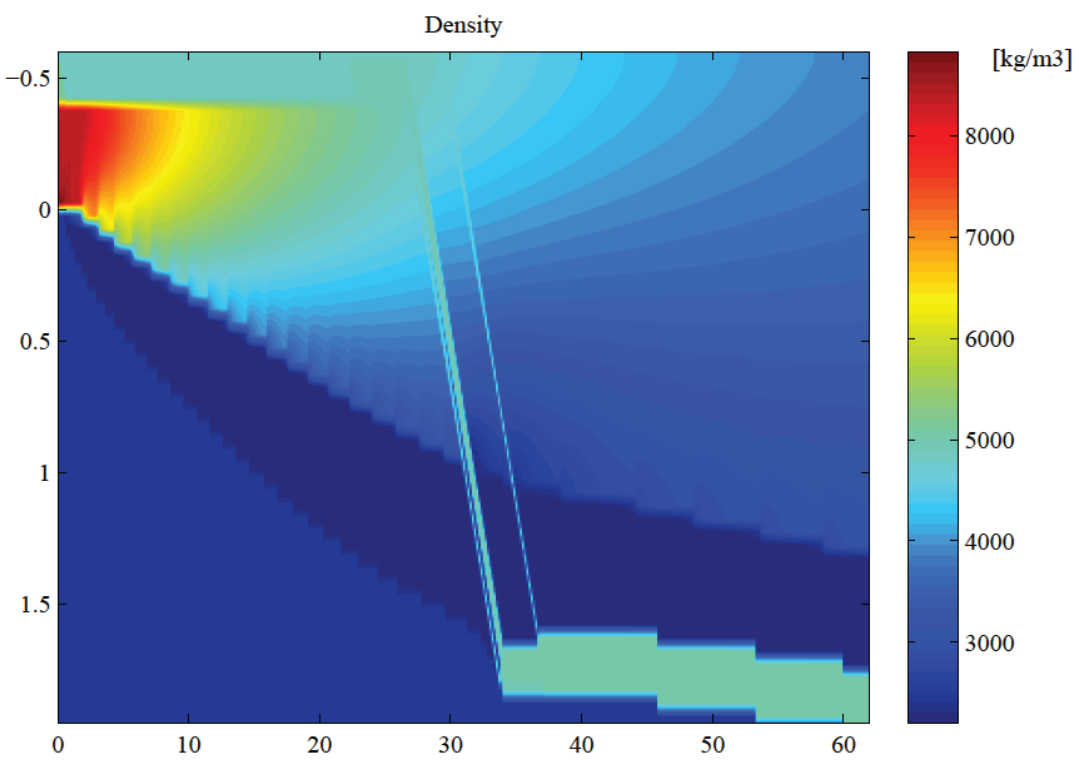

Fig. 12 Development of density for case with only siliceous aggregate.

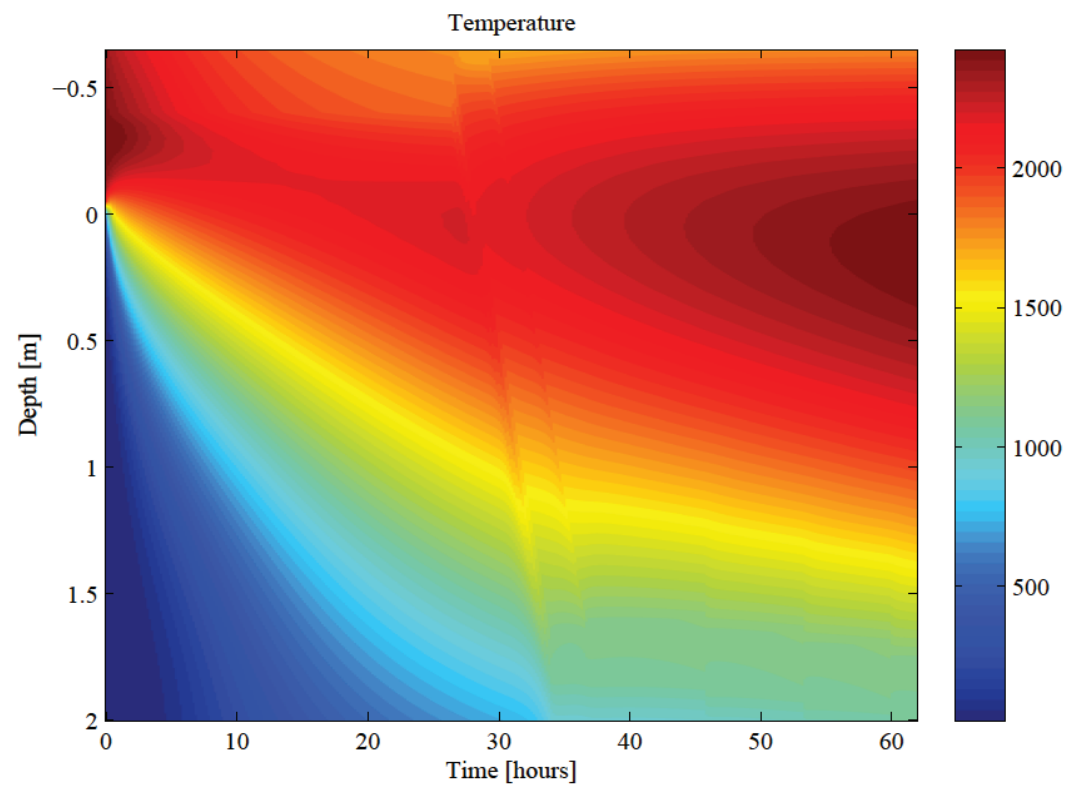

Fig. 13 Development of temperature for case with only siliceous aggregate. 
and concrete parts, of the pool is maintained at all times. The molten concrete and the oxidic corium mix together which causes the decrease in density of the oxidic part of the corium pool. The metallic layer then starts to sink under the oxide-concrete mixture when the density of the oxide-concrete part of the melt pool becomes less than that of the metallic layer. The sinking of the metallic layer occurs between 27 and 37 hours, as can be seen in Fig. 12. The sinking does not occur at one time because the metallic part has a different density at each layer (finite element) of the model. The top layer of the metallic part is cooled down by the ambient air and therefore has the highest density. As the layers with higher density sink first, the hottest part of the metal becomes the top layer. Since this topmost metallic part is warmer and thus with a lower density, the density of the oxidic part of the pool needs to decrease through the mixing with molten concrete before the rest of metals can sink under the oxide-concrete part of the melt pool, as can be seen in Fig. 12. The total ablation of the slab occurs at 60 hours. The process of the separate sinking of the metallic part of the melt pool is also visible in the temperature development shown in Fig. 13 as the two parallel lighter paths. Figs. 14 and 15 shown the density and temperature distribution over the thickness of the concrete slab at 10 and 33 hours when the progress of sinking of the metallic part is also well evindenced. The effect of insulation of the heat source is basically same in the stratified configuration of the melt pool.

\section{Comparison of computed results with literature}

The results of the two examples which are described in the previous section are compared with the results published in [1]. Fig. 16 shows the comparison of the ablated depth over time where the results of the proposed method are at the lower bound of the band which contains the up-to-date published simulation data for concrete with limestone aggregate. The results obtained at CEA and VTT were the lowermost and the uppermost results published in [1]. In this case, the melt pool is fully homogenized due to the considerable effect of mixing with the released gases from the limestone aggregate. In Fig. 17, the results of the proposed method are compared with experimental data from [1] for concrete with siliceous aggregate. Fig. 17 shows clearly the pronounced stratification between the metallic part and the oxide-concrete mixture within the melt pool, which is caused by the siliceous aggregate. The sudden increase in the ablation rate at the depth of 1.5 meters is caused by sinking of the metallic part through the oxide-concrete mixture of the melt pool (clearly seen in Figs. 12 and 13), which generates heat, and so the sinking metal accumulates some of the heat and due to its higher thermal conductivity heats up the concrete below and thus accelerates its ablation. The results of the proposed method are in this case also at the lower bound of the band of the data published in [1] for concrete with siliceous aggregate.

The differences in the comparison may seem large, but it should be noted that the data published in [1], which are the only publicly available relevant data to compare with, were obtained with different concrete mix designs (contents of water, cement, sand and gravel) and corium pool with different composition. Another 


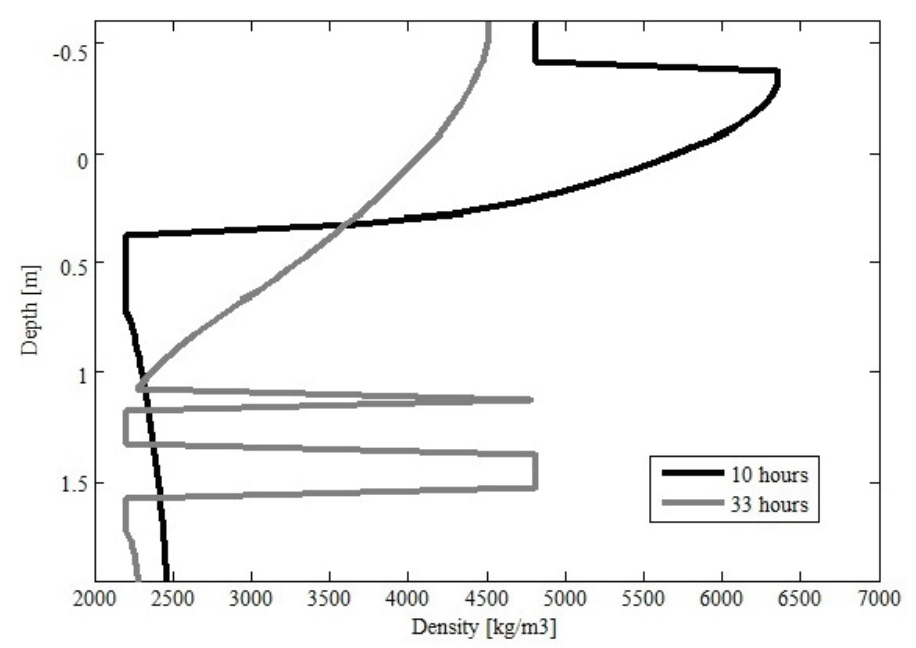

Fig. 14 Density distribution for case with only siliceous aggregate.

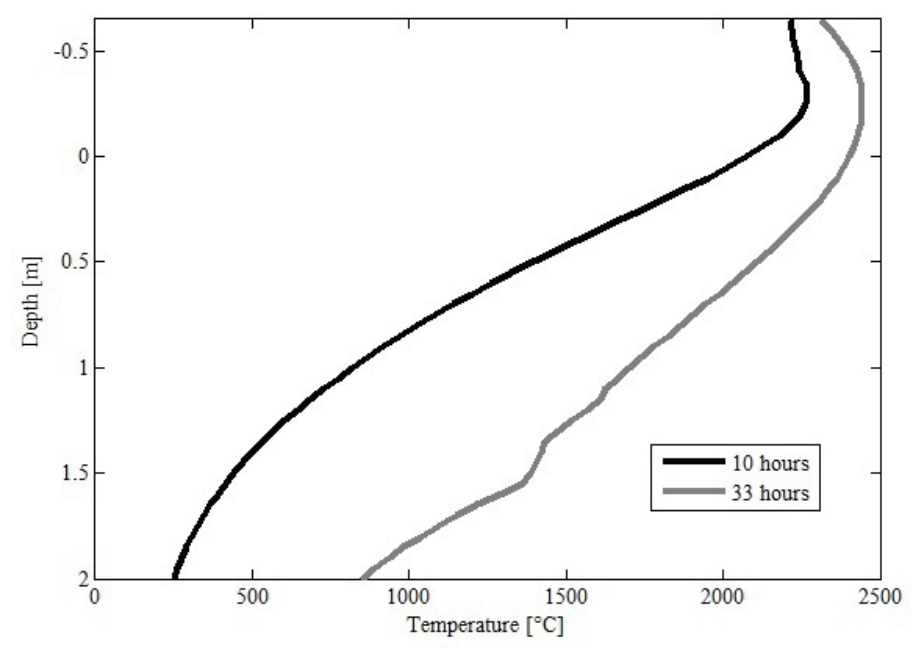

Fig. 15 Temperature distribution for case with only siliceous aggregate.

source of the underestimation of the ablation rate may come from the decay heat, which is not defined for the results in [1].

The heat generated by decay of the fission products in the oxidic part of the melt pool is expressed in the presented examples by the following function which is generally used for estimation of the residual heat during controlled shutdown of a reactor

$$
H=H_{0} \cdot 0.066\left(t^{-0.2}-\left(t+t_{0}\right)^{-0.2}\right),
$$


Vaitová M., Štemberk P.: Estimation of ablation depth in concrete slab under...

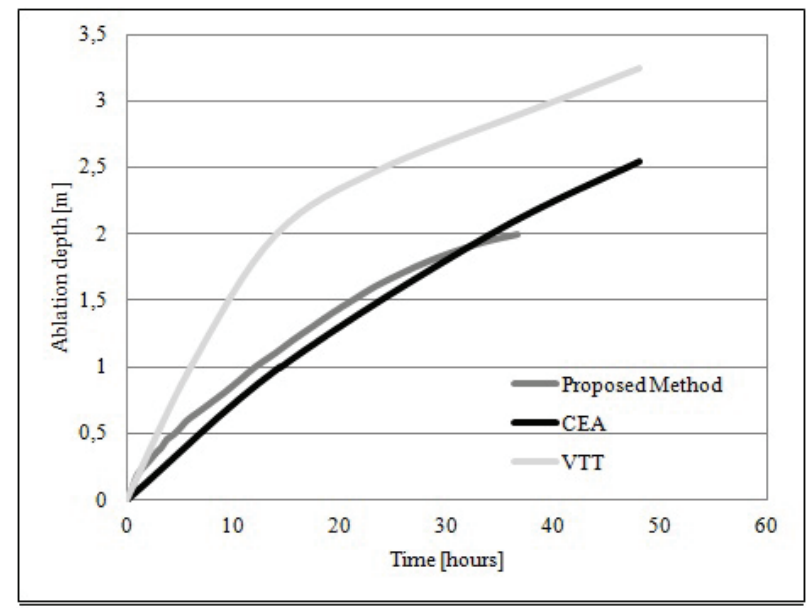

Fig. 16 Comparison of ablation rate for case with only limestone aggregate.

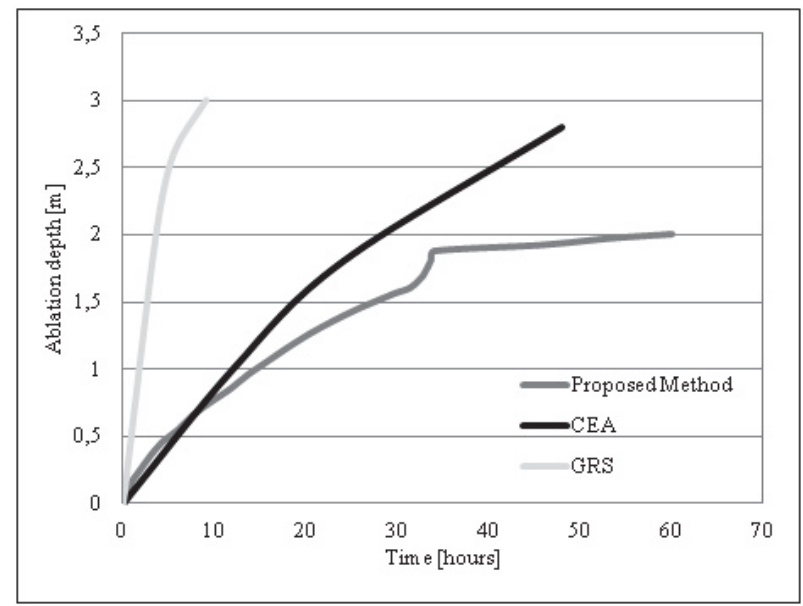

Fig. 17 Comparison of ablation rate for case with only siliceous aggregate.

where $H_{0}$ is the heat generation at the accident time (VVER 1000 with 66 tons of fuel generates $3000 \mathrm{MW}), t$ is the instant of the heat estimation and $t_{0}$ is duration of reactor operation, which is taken as 6 months. The use of this function may be one of the principal reasons for underestimation of the ablation rate when compared with other published data in [1] as in the case of the accident the generated heat would be higher than the heat considered in these examples. 


\section{Conclusions}

This paper presents a simple method for estimation of the ablation rate of the concrete base slab in the reactor cavity when the corium pool leaks from the overheated reactor. On the contrary to the highly specialized computer codes which require rather deep knowledge in various scientific fields, the problem here was approached in the traditional engineering manner when all important phenomena of the problem are expressed in the simplest possible and thus transparent way. Therefore, the fuzzy logic was employed as it allows direct conversion of the identified trends and verbal expressions into numbers, which can be then used in numerical algorithms.

The results obtained with the presented method provide estimates which are similar to the publicly available data on the ablation rate of concrete which is caused by the spilled corium pool. The obtained results show a consistent underestimation which is, most probably, caused by underestimation of the generated heat from decay of the fission products. It was also hinted that the comparison tries to match data which are not fully comparable due to differences in concrete and corium pool composition. Therefore, the results of the proposed method can be considered as another publicly available data which are calculated for the specific type of reactor, the VVER 1000. Then, the proposed method can be considered as fit for use for the preliminary estimation of ablation depth, which is necessary for ensuring safety when a nuclear accident happens.

However, the most proper conclusion of this study seems to be the declaration that the best way to avoid the severe accident disaster, especially after recent one at Fukushima-Daiichi is to install at the existing nuclear power plants cooling systems which will make sure that corium will never leak from the reactor pressure vessel, which is commonly known as the in-vessel-melt retention strategy.

\section{Acknowledgement}

The work was financially supported by the Czech Science Foundation, project 15$11753 \mathrm{~S}$, which is gratefully acknowledged.

\section{References}

[1] CRANGA M., SPINDLER B., DUFOUR E., DIMOV D., ATKHEN K., FOIT J., GARCIAMARTIN M., SEVÓN T., SCHMIDT W., SPENGLER C. Simulation of corium concrete interaction in 2D geometry. Progress in Nuclear Energy. 2010, 52(1), pp. 76-83, doi: 10.1016/j.pnucene.2009.09.016.

[2] DA SILVA W.R.L., ŠTEMBERK P. Shooting-inspired fuzzy logic expert system for readymixed concrete plants. Journal of Intelligent 63 Fuzzy Systems. 2013, 25(2), pp. 481-491, doi: $10.3233 /$ IFS-120655.

[3] FARMER M.T., LOMPERSKI S., KILSDONK D., AESCHLIMANN R.W., BASU S. A summary of findings from the melt coolability and concrete interaction (MCCI) program. In: Proceedings of the International Congress on Advances in Nuclear Power Plants (ICAPP'07), Nice, France. SFEN, 2007, 13 pp.

[4] GENCHEVA R., STEFANOVA A., GROUDEV P. ASTECv2/MEDICIS computer code investigation of influence of water content and carbon dioxide content in the concrete on the kinetics of molten coriumconcrete interaction. Nuclear Engineering and Design. 2013, 265, pp.625-632, doi: 10.1016/j.nucengdes.2013.06.022. 
Vaitová M., Štemberk P.: Estimation of ablation depth in concrete slab under...

[5] INTERNATIONAL ATOMIC ENERGY AGENCY. Thermophysical properties database of materials for light water reactors and heavy water reactors [online]. Vienna: International Atomic Energy Agency, 2006 [viewed 2015-01-28]. Final research report. Available from: http://www-pub.iaea.org/MTCD/publications/PDF/te_1496_web.pdf

[6] JOURNEAU CH., PILUSO P., HAQUET J.F., BOCCACCIO E., SALDO V., BONNET J.M., MALAVAL S., CARÉNINI L., BRISSONNEAU L. Two-dimensional interaction of oxidic corium with concretes: The VULCANO VB test series. Annals of Nuclear Energy. 2009, 36(10), pp. 1597-1613, doi: 10.1016/j.anucene.2009.07.006.

[7] KUMAR V., VENKATESH K., TIWARI R.P. A neurofuzzy technique to predict seismic liquefaction potential of soils. Neural Network World. 2014, 24(3), pp. 249-266, doi: 10.14311/NNW.2014.24.015.

[8] NAUS D.J. The effect of elevated temperature on concrete materials and structures-a literature review [online]. Oak Ridge: Oak Ridge National Laboratory, 2005 [viewed 2015-01-28]. Research report. Available from: http://info.ornl.gov/sites/publications/files/Pub1043.pdf

[9] NEVILLE A.M. Properties of concrete. 4th ed. New York: John Wiley, 1996.

[10] POKORNÁ N., ŠTEMBERK P. Fuzzy logic model for description of fatigue behavior of concrete. In: Proceedings of the 15th International Conference on Mechanika, Kaunas, Lithuania. 2010, pp. 351-355.

[11] ROY A.F.V., CHENGY M., WUY Y. Time dependent evolutionary fuzzy support vector machine inference model for predicting diaphragm wall deflection. Neural Network World. 2014, 24(2), pp. 193-210, doi: 10.14311/NNW.2014.24.012.

[12] SEILER J.M., GANZHORN J. Viscosities of corium-concrete mixtures. Nuclear Engineering and Design. 1997, 178(3), pp. 259-268, doi: 10.1016/S0029-5493(97)00232-X.

[13] SEVÓN T. Molten core - concrete interactions in nuclear accidents: Theory and Design of an Experimental Facility [online]. Espoo, 2005. Master Thesis, VTT Tiedotteita [viewed 2015-01-28]. Available from: http://www2.vtt.fi/inf/pdf/tiedotteet/2005/T2311.pdf

[14] SEVÓN T. A heat transfer analysis of the CCI experiments 1-3. Nuclear Engineering and Design. 2008, 238(9), pp. 2377-2386, doi: 10.1016/j.nucengdes.2008.02.002.

[15] SEVÓN T., JOURNEAU CH., FERRY L. VULCANO VB-U7 experiment on interaction between oxidic corium and hematite-containing concrete. Annals of Nuclear Energy. 2013, 59, pp. 224-229, doi: $10.1016 / \mathrm{j}$.anucene.2013.04.016.

[16] ŠTEMBERK P., DA SILVA W.R.L., SÝKOROVÁ J., BÁRTOVÁ J. Fuzzy modeling of combined effect of winter road maintenance and cyclic loading on concrete slab bridge. Advances in Engineering Software. 2013, 62-63, pp. 97-108, doi: 10.1016/j.advengsoft.2013.04.008.

[17] ŠTEMBERK P., RAINOVÁ A. Simulation of hydration and cracking propagation with temperature effect based on fuzzy logic theory. Mechanika. 2011, 4, pp. 358-362, doi: 10.5755/j01.mech.17.4.561.

[18] XUE X., LI Y., YANG X., CHEN X., XIANG J. Prediction of slope stability based on GA-BP hybrid algorithm. Neural Network World. 2015, 25(2), pp. 189-202, doi: 10.14311/NNW.2015.25.010. 
